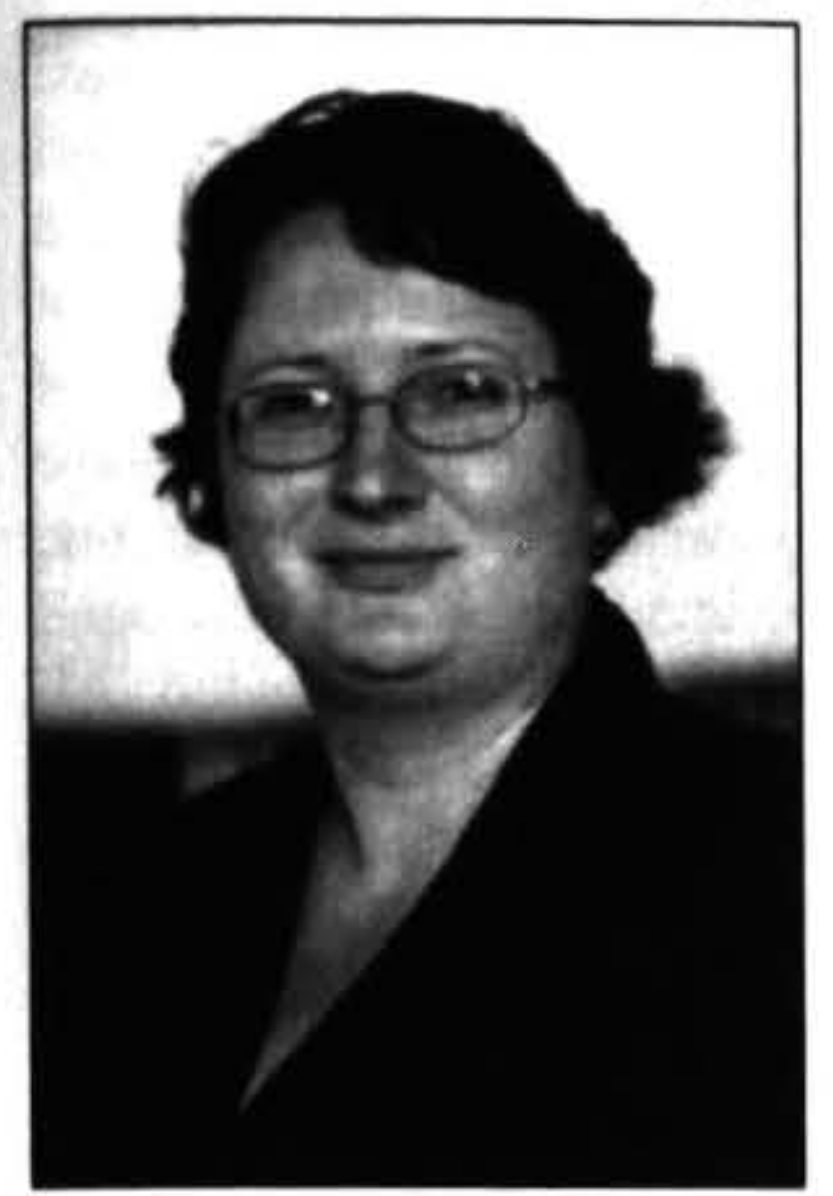

\title{
DECISIONS ABOUT CARING \\ AND WORKING: \\ A QUALITATIVE STUDY ${ }^{1}$
}

\author{
Kim Allen \\ Workforce Policy Research and Evaluation. \\ Department of Labour, Wellington
}

\begin{abstract}
The Department of Labour and the National Advisory Council on the Employment of Women (NACEW) commissioned research to identify the factors that influence people's decisions surrounding paid work, and to provide a better picture of the decision making process. Fifty qualitative interviews were undertaken with people with primary caring responsibilities for children and/or adults, or in a few cases, shared caring responsibility with their partner. This study found that multiple factors influence people's choices about paid work, and that different approaches suit different people in different situations. Participants made decisions that, as far as possible, balanced their beliefs about caring with their commitment to work and their need for intellectual satisfaction, social contact and money. Their decisions were based on their personal preferences, rather than on information about financial benefits or services that might support them in their role. The research also highlighted the importance of providing an environment that supports people's choices to be involved in employment, and to care for their loved ones. The study has identified a number of areas for further work.
\end{abstract}

\section{Introduction}

Although there have been many international and local studies related to combining paid work and parenting. there is limited qualitative research in New Zealand that looks specifically at factors influencing labour market decisions, and the decision making process for parents and people with other caring responsibilities.

The Department of Labour and the National Advisory Council on the Employment of Women (NACEW) commissioned research to identify the factors that influence people's decisions surrounding paid work, and to provide a better picture of the decision making process.

An overview of international research on families and paid work shows that most studies about families and paid work centre on the circumstances and choices made by low income and sole parents, or on improving outcomes for children from low income families. An increasing amount of attention is being paid to the paid work/caring dynamic for people caring for adults, but there appears to be limited literature that refers to workforce participation decisions made by people in a range of circumstances.

\section{Recent New Zealand Research}

A number of recent New Zealand reports focusing on paid work and parenting provide some context for this research.
Stephens and Callister (2006) show that New Zealand has a different pattern of participation by mothers of young children compared to other OECD countries. For partnered mothers, the pattern features a high rate of withdrawal from the labour market when children are very young, but high participation rates when children are school age. New Zealand has relatively low employment rates for sole mothers compared with many other countries, both when children are young and when they are at school.

The Work, Family and Parenting study (Ministry of Social Development, 2006) showed that 30 percent of two-parent households had made a conscious decision for one parent not to be in paid work in order to care for young children at home; while 40 percent of all parents said they chose to work shorter hours or fewer days because of family responsibilities (age and number of children not specified). Little is known about how people made these choices, what factors influenced their decisions, or what they aimed to achieve by making them.

In 2005, the Families Commission undertook 43 focus groups with a range of families as part of a larger project to improve understanding of successful outcomes for families with dependent children. The focus groups looked specifically at decision making among other topics, and found that while families recognised that poor decision making was detrimental to well being, few made an explicit link between decision making and successful outcomes. 
As might be expected, recent research has also made it clear that some parents find it difficult to juggle paid work and parenting. The Department of Labour (2006) report Work-Life Balance in New Zealand found that employees with carer responsibilities were more likely to experience work-life conflict. The home-to-work 'spillover' had a greater impact on home life than work life, but effects at work were still considerable. For example, carers were significantly more likely than others to report that life outside work sometimes had an impact on their ability to take up development and career opportunities, and to get to work on time. Those with pre-school children were more likely to say that life outside work affected their ability to concentrate when they are at work, and having enough energy to do the job.

The research on work/life balance shows that achieving a balance is situation specific and affected by many factors, including individual choice or preference, employer/employee relationships and government policies. Therefore no single policy or support arrangement for achieving a balance will meet everyone's needs. Studies that look in depth at people's circumstances, and the factors influencing their decisions, will be an important source of information for the ongoing discussion about work-life balance.

\section{Purpose of Research and Methodology}

The current research aimed to increase understanding about the decisions men and women who have caring responsibilities make about whether, how, when and why they participate in paid work. A secondary objective was to examine whether information on the consequences of decisions about paid work had an impact on these decisions.

Fifty qualitative interviews were undertaken with people who had primary caring responsibilities for children and/or adults. or in a few cases, shared caring responsibility equally with their partner. The qualitative approach allowed in depth exploration of the research topics. Having a sample with a number of different characteristics provided breadth but the small sample size means that the findings cannot be generalised to the population as a whole (e.g. not all men will feel the same way as the men in the sample). At the same time, the interviews did produce some consistent findings and highlighted areas for further research.

The population of interest was people with at least one child up to the age of eighteen years, including parents of children with special needs, and people who have caring responsibilities for another adult, including adults with disabilities and older adults. Researchers used the snowball technique to select 50 people with caring responsibilities from Wellington. Auckland, Nelson (and Motucka) and the Wairarapa. The data was transcribed and coded into an NVivo database, and analysed thematically.
The sample included a range of participants: people aged between 20 and 65; men and women; European, Maori and Pacific people; living rurally, in small towns and urban centres. It included a disproportionate number of participants with tertiary qualifications and levels of income above the national average. Other studies have tended to focus on those with low income or sole parents; this study has a mix of income levels, particularly around those in the higher brackets who are often excluded. All but one participant cared for children, and a quarter cared for children with special needs or an adult with a disability. One person cared for an adult only.

Participants were in part time and full time paid work, or not in paid work. People usually stopped paid work upon the birth of a child, going back part or full time as their youngest child went to school. People who worked few or irregular hours were usually contractors; those who worked longer, more regular part time hours or full time were almost all employees.

\section{Discussion of Main Findings}

This study identified two broad patterns of decision making about parents participation in paid work. In one pattern, a parent (usually but not always the mother) left paid work to care for a baby and resumed work when the child was older. This is in accord with the pattern described by Stephens and Callister (2006). The second, less common pattern was for both parents to remain in fulltime work, with a period of parental leave for one of them.

People with caring responsibilities for adults or for children with special needs had similar patterns of participation in paid work. This may be because all but one of the participants in this study had caring responsibilities for children. Given the nature of the sample, these results are not necessarily typical of the situation in New Zealand. Further research is needed into the participation in paid work of people who have caring responsibilities only for adults, particularly adults who live with the carer and adults with disabilities, and people who have caring responsibilities only for children with special needs.

The participants in this study based their decisions about paid work on a combination of factors involving parental/family care of children. financial factors and other factors

\section{Parental/Family Care of Children}

Beliefs about parental/family care for children underpinned most participants decisions. Men and women across all categories of involvement in paid work felt strongly that parents/family should provide all or most of the care for very young children, and for some parents, for dependent children of any age. The age of their youngest child had a strong influence on almost all participants participation in paid work. For example, one participant, who worked as a teacher aide at the 
kindergarten where her son went, said:

\begin{abstract}
I haven't worked until the last year when he started kindergarten and I am there with him. All activities are around him - he is the primary factor [in relation to work situation]. I want to be there for him. A parent should be at home. I believe in parental care. When I work at the kindv, I am part of his life. I do it because he is there.
\end{abstract}

Regardless of their income, occupation, or level of education, participants did not want pre-school children, particularly those under two, in full day centre-based services. Another participant mentioned that:

\begin{abstract}
We're not into childcare - too many kids [at centres]. We wanted to have one parent at home. Maybe the kids get socialisation [at a centre] - I don't know but there's not enough one on one.
\end{abstract}

As children got older, parents were more willing to use part time centre-based services and other formal early childhood education such as playcentre, kohanga reo, and kindergarten, usually for the opportunity for their children to interact with other children. Only parents who had preschool children and worked full time used these services to enable them to work.

The importance of wider family in providing care for children and general support for parents across all ethnic groups is a key finding of this and other recent studies (e.g. Ministry of Social Development, 2006; Department of Labour and NACEW, 1999). For example, one study participant highlighted the importance of her family in facilitating her return to work:

Having support from family enabled early return to full time work. I would not have gone back so early if my mother was not there.

\section{Financial Factors}

All participants took their financial circumstances into account when making decisions. However, people's actual personal and household income appeared to have no relationship to their views about whether they needed to be in paid work for the income, or could afford to have one parent work part time or not at all. Income from work was an important factor in the decision for people working longer part time hours and full time. One participant who was a single parent and who had worked full-time since her child's birth stated that:

\footnotetext{
[Work] is about stability and commitment and participation, contribution, giving back and remuneration... I have chosen to prioritise financial security as opposed to being an actively involved parent.
}

For people with partners, and particularly for men, relative incomes were important in deciding who would be the primary caregiver. However, men who were in fulltime work and took on the primary caregiver role did so for other reasons as well, such as working evening shifts or having flexible employment.

\section{Other Factors}

Work related factors such as personal satisfaction, intellectual stimulation, and feeling valued were also strong influences on people's decisions to be in paid work, both part and full time. For example, one participant believed that:

\section{Paid work is really important. I understand the value it gives to people feelings of value and contribution. and food and being able to provide for the children.}

Although they did not discuss the quality of their work in any depth, a majority of those in full-time work were in jobs that paid well above the national average. These are likely to be jobs that provide both intellectual stimulation and personal satisfaction. The findings align with recent research into balancing work and caring responsibilities, where a majority of respondents would prefer to have a job even if they had a reasonable living without one (Department of Labour 2003 and 2006; Families Commission 2005; Ministry of Social Development 2006).

Employers' and colleagues' attitudes, and workplace flexibility, such as glide time, working at home and an ability to work part time, were significant but not the strongest factors in people's decisions about participating in paid work. They were more important for people with older children who considered them in combination with other factors, such as family support for caring for children. Another participant stated that:

There's a huge amount of networking
before 9am and after $5 \mathrm{pm}$. and I am not
able to participate in that.

Acceptance of traditional gender roles was a decisive factor for some participants, and underpinned other participants' decisions. The latter group did not necessarily hold traditional views about gender roles, but slipped into these roles once a child was born. For example, they may have shared domestic work before they had a child but did not do so afterwards. A recent Ministry of Social Development study found that about a third of adults with families believe that the father should earn the family income and the mother should stay at home (Ministry of Social Development 2006).

A range of other factors working in combination had some influence on decisions. These included living in a rural area, having more than two children, being unable to drive, and having spent years out of the paid workforce. People also made decisions to change their hours of paid 
work because they wanted to study, or because particular work opportunities arose.

People made their decisions for personal reasons. They did not consider the state of the labour market, or the effects of government policies. The lack of discussion about the cost of childcare may reflect the relative affluence of the sample. It is interesting in the light of the 2004 Living Standards study, which found that families who identified cost as a reason for not using childcare were more likely to be in some degree of hardship than other families with dependent children.

It is unclear whether New Zealand's comparatively low rate of employment among mothers of pre-school children reflects active choices by parents or constraints on choices due to lack of support in areas such as childcare. This study suggests that, for this sample at least, the lower rate of employment largely reflects an active choice.

Similar factors influenced decisions of people from different ethnic, age, income and occupational groups, with the exception of managers who felt that they needed to work full time even if this was not their preference.

\section{Factors for Specific Groups of People}

Caring for a child with special needs or an adult with disabilities was an added stress in people's lives. but the type of caring responsibility did not, in itself, appear to drive their decisions about participation in paid work. People who cared for children with special needs or adults with disabilities made their decisions on similar grounds to those caring for children generally. Caring for older adults without disabilities did not influence people's decisions about participation in paid work, although it did affect the time they had for other activities. One participant mentioned that:

\begin{abstract}
My aged parents are not in lthe city I live iin). My mother is in hospital with severe dementia. Mis father is at home ... his health is just deteriorating now: My weekends are spent up there helping him. I rake time from work to do this, for example. I hare taken my father to hospital for appointments four times in the last month. I get paid hourly so if I'm not there I don't get paid and that makes a difference.
\end{abstract}

Single people made decisions based on a similar range of factors as partnered parents. Some single people had high levels of family support, including from their ex partner and his or her family; others did not. Recent studies have found that the largest difference between single and partnered parents is the amount of money, and for some. the amount of time they have for themselves, rather than the factors that shape their decision to be in paid work (Ministry of Social Development, 2006; Families Commission, 2005).
A key finding from this and other recent research is that people are influenced in their choices by many factors, and that different situations suit different people.

\section{Decision Making Processes}

Most people felt they had choice and control over their decisions about paid work, although some felt obliged by circumstances such as a partner's inability to care for children, to be in their situation. This was particularly the case for men who were primary caregivers and not in any paid work. People discussed decisions with partners where they had them, and sometimes with immediate family. Other people were largely supportive of whatever decision people made. Negative attitudes had no material effect on decisions.

Most people found decision making straightforward. Decisions about participation in paid work evolved over time, and built on earlier decisions and experiences such as choice of occupation and where to live, experiences at school, and family patterns in childhood.

The study explored whether people sought information to help them make decisions. No participant looked for information about what support was available, or the longer term financial or career effects of not working or reducing hours in paid work. Participants were aware of debate around longer term effects of formal early childhood education or informal childcare, although they did not seek this information out to help them decide whether or not to participate in paid work. A quote from one of participants illustrated this point:

\section{I haven't looked at longer term financial impacts - what will be, will be. Money is not the most important thing. I talked to my cousin who is a teacher about differences with kids who have a parent at home [in terms of] children's behaviour and attitudes and that has reinforced to me that long term I am doing the right thing with my'son.}

Because no participant had robust, or in most cases, any external information about the implications of their choice, it was impossible to assess the impact of information on decision making. Research carried out by the Families Commission in 2005 found that few families made explicit links between decision making and successful outcomes. The findings of this study suggest that people are obliged to respond to their immediate and short term needs, and cannot always take into account long term effects even if aware of them.

\section{Effects of Decisions}

Another issue is whether time out of the workforce has adverse effects on future employment or promotion prospects. 
In this study, caring responsibilities had positive and negative effects on people in all paid work categories. Some people not in paid work or working few hours felt they would not be able to return to highly paid and demanding jobs, and still fulfill their caring responsibilities. They chose to leave work or consider retraining for a position they could do part time. Others took the opportunity while away from full time work to study, aiming for a better paid and more satisfying job when they returned to work.

People working full time were unable to attend professional development and networking opportunities; others were reluctant to leave employers who offered flexible arrangements to pursue career development. An example of this was mentioned by one of the study participants:

\begin{abstract}
Lots of times I would like to go on training but I don't because of having a child. Having a child has held me back because my first thought always has to be for home. There are lots of positions, extra responsibility that came up in $\mathrm{mv}$ job but I can't... I did get [a promotion] but resigned because I realised hefore I even started that I couldn't do it with [my child] as this would take me away from being a mother.
\end{abstract}

This study shows that it is not so much that people cannot progress in jobs or access training when they have caring responsibilities, but that some choose to prioritise their caring responsibilities while others find it too hard to combine work and caregiving. They include people who are single, have a partner with an inflexible job or one that requires travel, live rurally, have more than two children, and have children with special needs that require varying and/or unpredictable levels of extra care.

Another issue is the effect of parents' decisions about participation in paid work on children. Stephens and Callister (2006) summarise the literature in relation to pre-schoolers as follows:

\begin{abstract}
On the one hand, additional income from employment reduces the impact that poverty has on child attainments... On the other hand, maternal employment increases stress and reduces the availability of time for child-rearing, both of which can adversely affect child outcomes. However. the trade-off between these two varies by age group, with a general impression that for the first year of life, the child is probably better at home with a parent, and between ages three and five some form of quality child interaction is desirable, with a grey area for children aged one and two.
\end{abstract}

This summary reflects the values and practice of almost all the people in this study.
Men and women in this study who had with school aged children and had reduced their hours of paid work felt this was positive for family relationships. They had more time with their children. People in full time work felt that, while they were role models for their children and the family had more money, they missed out on time with their children and participating in school activities. These findings are consistent with other research (Ministry of Social Development, 2006; Families Commission 2005). This study included only parents' views, but the Families Commission research included focus groups with children. Their views about parents working were similar to their parents: there was more financial freedom, but they spent less time together. For children, some of the additional benefits of parents working were more privacy to do what they wanted, having the house to themselves, and having more takeaway meals. Exploring optimal outcomes for children of all ages could feature more prominently in research into balancing work and caring responsibilities.

The study showed a relationship between being the primary caregiver and being responsible for all unpaid work in the household. The primary caregiver for the children did domestic work in the household regardless of whether they were in any paid work, and irrespective of gender. In households with two working parents, domestic work tended to be shared, although women took more responsibility for organising it. This finding diverges from other research showing that women do more domestic work than men, even when both partners in a household are in full time paid work (Ministry of Social Development 2006). If there is interest in exploring the relationships between caring responsibilities, paid work and unpaid domestic work further, case study research gaining the views of different people in a household would be useful.

\section{Satisfaction with Decisions}

Participants felt that society did not value their work as carers, even though they personally valued this role highly and were satisfied with their decisions. People not in paid work were most affected by this, as others derived social value from their paid work. All participants thought it was beneficial for parents to be with children, especially young children. Men in particular reflected on the value and importance of building strong relationships with their children. One participant believed that:

$$
\begin{aligned}
& \text { If we valued parenting and stay at home } \\
& \text { parents we would not have half the issues } \\
& \text { we do - if we enhanced and facilitated the } \\
& \text { role. }
\end{aligned}
$$

While people in part time work found elements of both caring and working satisfying, they were not satisfied with having to juggle two roles and make compromises with both. People in full time paid work also had to juggle two roles and had less time for parenting and for themselves than they would like. This finding is supported by recent research, which shows that most 
people are satisfied with their work/home situation, even though it is not their ideal (Families Commission, 2005; Ministry of Social Development, 2006).

Most people found decision making straightforward. Their choices were clear cut and they could not identify ways to make decision making easier. However, they did discuss changes that might make their lives easier, for example, having more family close by who could provide support.

Participants who had high levels of flexibility within their employment were more satisfied, and found it easier to manage their caring and paid work responsibilities, than those who did not. Some participants in paid work felt their lives would be easier if employers took a more active and lateral approach to workplace flexibility.

On the whole, the study concurred with other recent research which shows that many people do have access to various types of flexible work options, but their ability to use them depends on a variety of factors, including workplace culture (Ministry of Social Development, 2006: Department of Labour, 2003, 2006). Some people in the study changed jobs to obtain flexible conditions.

This, and other recent research into work-life balance, suggests that individuals and families establish priorities, are able to arrange situations that more or less suit these priorities, and on the whole, are satisfied with their lives at work and home. In summary, this study is in accord with other research findings on:

- mothers pattern of participation in paid work

- parents extensive use of informal childcare. particularly for children under the age of two

- the influence of beliefs about traditional gender roles

- the importance of financial factors in making a decision about participating in paid work

- the importance of factors such as personal satisfaction, intellectual stimulation and feeling valued in making a decision

- the similarity of factors influencing single and partnered parents' decision making

- the lack of a longer term view in decision-making

- the benefits of flexible workplace conditions

- people's generally high levels of satisfaction with their decision.

This study showed that, when making a decision, participants did not actively seek information on services and financial benefits available to support them in their role as caregivers, nor did they specifically seek information on the long-term consequences of their decision. However, this does not mean that information should not be provided or made available.

\section{Conclusions}

This study has shown that multiple factors influence people's choices about paid work, and that different approaches suit different people in different situations.
The research also highlighted the importance of providing an environment that supports people's choices to be involved in employment, and to care for their loved ones.

\section{Future Research}

Participants made decisions that, as far as possible, balanced their beliefs about caring with their commitment to work and their need for intellectual satisfaction, social contact and money. They based their decisions on personal preferences, rather than on information about financial benefits or services that might support them in their role.

The study has identified a number of areas for further work. These include exploring the experiences and views of a wider variety of people; understanding men's situations better; developing ways to support people's preference to care for very young children (those under the age of two) themselves; exploring ways to support people's preferences for family and other informal care for children; promoting flexible working; and exploring the relevance of the nature and quality of work in decision making.

\section{Note}

1 This paper is based on the research report 'Decisions about caring and working: A qualitative study' published by the Department of Labour.

\section{References}

Department of Labour (2006). Decisions About Caring and Working: A Qualitative Study. Wellington: Department of Labour.

Department of Labour (2006). Work-Life Balance in New Zealand: A Snapshot of Employee and Employer Attitudes and Experiences. Wellington: Department of Labour.

Department of Labour (2003). Perceptions and Attitudes Towards Work-Life Balance in New Zealand - A Qualitative Studt: Wellington: Department of Labour.

Department of Labour and National Advisory Council on the Employment of Women (1999). Childcare, Families and Work: The New Zealand Childcare Survey 1998. Wellington: Department of Labour and National Advisory Council on the Employment of Women.

Families Commission (2005). Successful Outcomes for Families with Dependent Children - A Qualitative Study: Wellington: Families Commission.

Ministry of Education (2004). Early Childhood Education Statistics 2004. Accessed 25 June 2006: http://educationcounts.edcentre.govt.nz/statistics 
Ministry of Social Development (2006). Work, Family and Parenting Study: Research Findings. Wellington: Ministry of Social Development.

Ministry of Social Development (2006a). New Zealand Living Standards 2004. Wellington: Ministry of Social Development.

Stephens, B. and Callister, P. (2006). An optimal worklife balance for parents?: International comparisons and policy levers. Draft paper presented at the Reconciling Work and Family: Research and Policy Perspectives Conference, 21 April 2006. http://www.vuw.ac.nz/ips/ conferences/Work-life_balance.aspx

\section{Author}

Kim Allen

Senior Research Analyst

Workforce Policy Research and Evaluation Department of Labour

P.O. Box 3705

Wellington

Kim.Allen@dol.govt.nz 